\title{
KORELASI NILAI CBR TERHADAP TEGANGAN VERTIKAL DAN TEGANGAN HORIZONTAL PADA TANAH LEMPUNG DI DAERAH SENTUL
}

\author{
Edwin Wongkar ${ }^{1}$, dan Alfred Jonathan Susilo ${ }^{2}$ \\ ${ }^{1}$ Program Studi Sarjana Teknik Sipil, Universitas Tarumanagara, Jl. Letjen S. Parman No.1 Jakarta \\ Email:edwinfw69@gmail.com \\ ${ }^{2}$ Program Studi Sarjana Teknik Sipil, Universitas Tarumanagara, Jl. Letjen S. Parman No.1 Jakarta \\ Email: alfredsusilo@gmail.com
}

\begin{abstract}
ABSTRAK
Tanah merupakan material yang sangat berpengaruh dalam pekerjaan konstruksi, karena kondisi tanah di suatu tempat tidak akan sama dengan kondisi tanah tempat lain. Oleh sebab itu, kondisi tanah dan sifat fisiknya harus diketahui terlebih dahulu. Sebagian besar wilayah Indonesia terutama di Jakarta merupakan tanah yang bersifat lempung. Beberapa masalah utama pada tanah lempung adalah settlement yang besar dan daya dukung yang kecil. Daya tahanan tanah dapat ditentukan dengan cara California Bearing Ratio (CBR) yang dilakukan di laboratorium. Penelitian CBR ini dilakukan korelasi antara nilai CBR terhadap tegangan vertikal dan tegangan horizontal sampel tanah. Sampel tanah yang diuji pada penelitian ini berasal dari Jl. Babakan-sirkuit, Tangkil, Citeureup, Bogor, Jawa Barat, Indonesia. Sampel tanah untuk pengujian CBR laboratorium dibuat dengan pemadatan $2.5 \%$, $5.0 \%, 7.5 \%$, dan $10 \%$. Hasil penelitian menunjukan persentase kenaikan nilai Su pada kepadatan $2.5 \%$ ke $5.0 \%$ adalah sebesar $22.51 \%$ untuk posisi vertikal, dan $45.58 \%$ untuk posisi horizontal. Pada kepadatan $5.0 \%$ ke $7.5 \%$ terjadi peningkatan nilai Su sebesar $17.14 \%$ pada posisi vertikal, dan $15.67 \%$ untuk posisi horizontal. Selanjutnya pada kepadatan $7.5 \%$ ke $10 \%$ terjadi peningkatan nilai Su sebesar $32.70 \%$ pada posisi vertikal dan $22.32 \%$ pada posisi horizontal
\end{abstract}

Kata kunci: tanah lempung, settlement, at-rest earth pressure, california bearing ratio (CBR), handheld vane shear.

\section{PENDAHULUAN}

Perkembangan di Jakarta tentunya membuat kebutuhan masyarakat dalam pembangunan infrastruktur dan bangunan lainnya semakin meningkat. Tanah merupakan dasar konstruksi yang memiliki keunikan tersendiri sehingga dalam pelaksanaannya proses mendesain konstruksi tidak dapat disamaratakan, hal ini menjadikan tanah sebagai hal yang perlu diuji dan diperhatikan. Tanah lempung merupakan salah satu tanah yang perlu diperhatikan karena kuat geser yang rendah jika terkena air. Kuat geser tanah lempung akan berkurang apabila kadar airnya bertambah dan struktur tanah juga akan menjadi terganggu (Ir.Hadiyatmo, 2002). Proses perbaikan yang ideal dilakukan pada tanah lempung adalah dengan melakukan pemadatan tanah. Tingkat pemadatan tanah yang dilakukan di tanah lempung dapat diuji dengan cara tes CBR. Tujuan dilakukan pengujian CBR ini adalah untuk mengetahui nilai CBR pada variasi kadar air pemadatan, dimana semakin tinggi nilai CBR tanah maka daya dukung tanah juga semakin tinggi, begitu juga sebaliknya semakin kecil nilai CBR tanah maka daya dukung tanah akan semakin rendah (Budi, 2011). Akan tetapi dalam proses penelitian selama ini perhatian lebih ditunjukan terhadap tegangan vertikal, dan tegangan horizontal sering diabaikan. Pada penelitian ini akan dilakukan korelasi antara kenaikan tegangan vertikal terhadap kenaikan tegangan horizontal. Sehingga ketika dilakukan pemadatan dan pengujian CBR terhadap tanah lempung, dapat memprediksi perbandingan kenaikan nilai tegangan vertikal terhadap tegangan horizontal

Dari penjelasan diatas akan dilakukan penelitian mengenai pemadatan tanah dan pengujian CBR, dengan pencapaian nilai CBR sebesar 2.5\%, 5.0\%, 7.5\%, dan 10\%. Dan selanjutnya dalam pengujian akan ditinjau tegangan vertikal dan tegangan horizontal dengan menggunakan metode Handheld Vane Shear dengan standar ASTM D8121. Serta menghitung korelasi persen kenaikan nilai tegangan vertikal dan tegangan horizontal terhadap kenaikan nilai CBR.

\section{TINJAUAN PUSTAKA}

\section{Studi Pustaka}

Tahapan awal untuk memulai penelitian ini yaitu dengan melakukan pencarian referensi yang memiliki informasi mengenai definisi, fungsi, dan tujuan, serta langkah-langkah kerja dari pengujian karakteristik tanah seperti uji kadar air, uji gravitasi khusus, uji batas konsistensi, analisa saringan, analisa hidrometer, kompaksi, CBR, dan uji 
Handheld Vane Shear serta melakukan perhitungan nilai koefisien At-Rest Earth Pressure $\left(\mathrm{K}_{0}\right)$. Standar yang digunakan dalam penelitian ini diambil dari ASTM (American Society for Testing and Materials).

\section{California Bearing Ratio (CBR)}

Uji CBR dilakukan dengan standar ASTM D1883. Nilai CBR didefinisikan sebagai suatu perbandingan antara beban percobaan (test load) dengan beban standar (standard load) dan dinyatakan dalam bentuk persentase. Tujuan dari pengujian CBR ini adalah untuk mengetahui nilai CBR pada variasi kadar air pemadatan. Untuk menentukan kekuatan lapisan tanah dasar dengan cara percobaan CBR diperoleh nilai yang kemudian dipakai untuk menentukan tebal perkerasan yang diperlukan diatas lapisan yang nilai CBRnya tertentu (Wesley 1977). Rumus CBR dinyatakan sebagai:

$$
C B R=\frac{P T}{P S} \times 100 \%
$$

Dimana CBR = California Bearing Ratio $(\%), \mathrm{PT}=$ Beban Percobaan $($ test load $)$, dan PS = Beban Standar (standard load)

\section{Handheld Vane Shear}

Handheld Vane Shear merupakan alat uji genggam yang memiliki baling-baling yang digunakan untuk pengujian kekuatan geser pada tanah kohesif secara cepat di laboratorium maupun dilapangan. Dengan ukuran yang kecil, alat ini memungkinkan pengujian kuat geser dilakukan di sisi lubang uji, parit, atau penggalian. Tes ini juga dapat dilakukan pada ujung-ujung tembok tipis, atau split spoon samples, dan sampel tanah dari proses galian. Handheld Vane Shear memiliki rentang tegangan dari $0.0-1.0$ tsf $\left(1.0937 \mathrm{~kg} / \mathrm{cm}^{2}\right)$. Berdasarkan rentang tegangan ini, alat ini memungkinkan untuk digunakan pada tanah lempung yang konsistensinya bervariasi yaitu dari yang very soft sampai stiff. Kekuatan geser tanah kohesif tergantung kepada banyak faktor, Handheld Vane Shear tidak menghilangkan efek dari salah satu faktor ini. Alat Handheld Vane Shear memiliki tiga ukuran baling-baling untuk memungkinkan pengujian dalam beberapa jenis konsistensi pada tanah lempung. Ketiga ukuran baling-baling Handheld Vane Shear yaitu berukuran standar $\left(0.0-1.0 \mathrm{~kg} / \mathrm{cm}^{2}\right)$ ukuran ini memungkinkan penggunaan pada tanah lempung yang konsistensinya bervariasi yaitu dari very soft sampai stiff. Kedua ada baling-baling berukuran besar $\left(0.2 \mathrm{~kg} / \mathrm{cm}^{2}\right)$ biasanya digunakan pada sampel yang telah dibuat ulang ataupun pada tanah lempung yang konsistensinya very soft. Terakhir baling-baling berukuran kecil $\left(2.5 \mathrm{~kg} / \mathrm{cm}^{2}\right)$ untuk tanah lempung yang memiliki konsistensi stiff.

\section{Koefisien At-Rest Earth Pressure $\left(\mathrm{K}_{0}\right)$}

$\mathrm{K}_{0}$ adalah koefisien tekanan lateral in-situ. $\mathrm{K}_{0}$ dapat diukur langsung menggunakan tes Dilatometer (DMT) dan Borehole Pressuremeter Test (PMT), akan tetapi penggunaan pengujian diatas sangat membutuhkan biaya, sehingga dibuat rumus hubungan empiris untuk memprediksi $\mathrm{K}_{0}$ dengan sedikit melibatkan pengujian tanah dan berhubungan dengan sudut ketahanan geser pada buku Physical and Geotechnical Properties of Soils yang mengacu pada rumus yang diajukan oleh Jaky (1948). Rumus yang digunakan untuk tanah terkonsolidasi normal dapat dihitung dengan:

$$
K_{0}=1-\sin \phi
$$

Dimana $\varnothing=$ Sudut geser dalam.

Untuk tanah fined-grained lempung, terkonsolidasi normal diuji kembali oleh Massarasch (1979) sehingga mendapatkan rumus empiris yang kedua yaitu:

$$
K_{0}=0.44+0.42\left[\frac{P I(\%)}{100}\right]
$$

Dimana PI = Indeks Plastisitas.

Untuk mendapatkan nilai sudut geser dalam $(\varnothing)$, digunakan beberapa rumus empiris. Salah satu rumus empiris dalam laporan Updating Bearing Capacity - SPT Graphs, yang ditemukan oleh Sowers pada tahun 1979 yang dapat dinyatakan sebagai berikut:

$$
S u=(0.102 t o 0.179) N S p t
$$

Setelah mendapat nilai NSpt digunakan interpolasi linear terhadap nilai sudut geser yang terdapat dalam tabel 2.6 yang ditemukan oleh Meyerhoff pada tahun 1956 dimana tabelnya dapat dilampirkan sebagai berikut: 
Tabel 1. Perbandingan Antar Nilai NSpt dengan Nilai Sudut Geser Dalam

\begin{tabular}{cccc}
\hline $\begin{array}{c}\text { SPT N } \\
(\text { Blows } / 0.3 m)\end{array}$ & Soil Packing & $\begin{array}{c}\text { Relative Density } \\
(\%)\end{array}$ & $\begin{array}{c}\text { Friction Angle } \\
\left({ }^{\circ}\right)\end{array}$ \\
\hline$<4$ & Very Loose & $<20$ & $<30$ \\
\hline 4 to 10 & Loose & 20 to 40 & 30 to 35 \\
\hline 10 to 30 & Compact & 40 to 60 & 35 to 40 \\
\hline 30 to 50 & Dense & 60 to 80 & 40 to 45 \\
\hline$>50$ & Very Dense & $>80$ & $>45$ \\
\hline
\end{tabular}

\section{METODOLOGI PENELITIAN}

Tahapan penelitian yang dilakukan adalah pengambilan sampel tanah, pengujian sifat-sifat tanah, klasifikasi dan karakteristik tanah, pemadatan tanah, dan pengujian menggunakan handheld vane shear. Secara umum tahapan penelitian dapat dilihat pada diagram alir pada gambar 1.

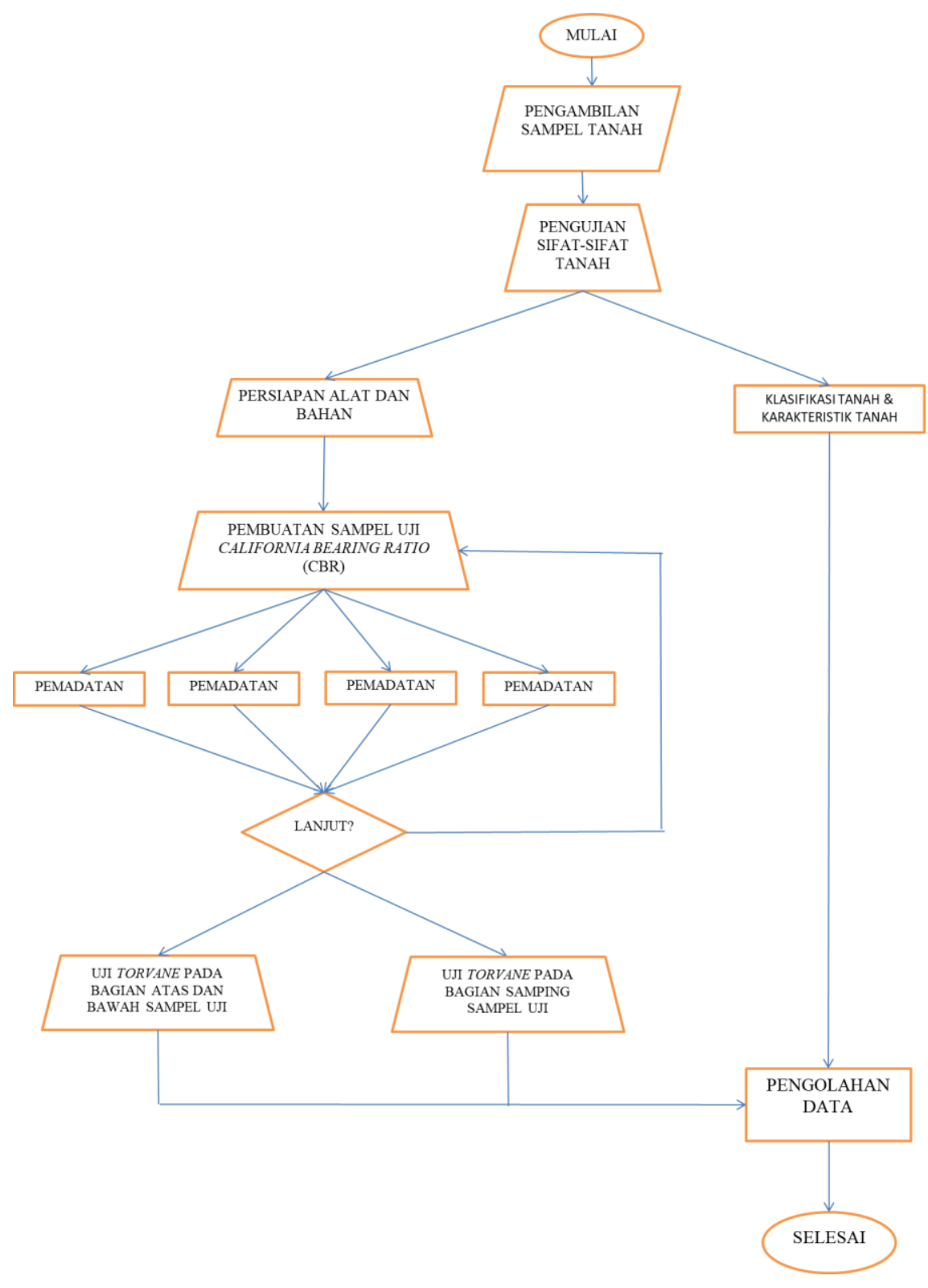

Gambar 1. Diagram Alir 


\section{Pengambilan Sampel Tanah}

Pada penelitian ini sampel yang digunakan diambil pada lokasi proyek di Jl. Babakan-sirkuit, Tangkil, Citeureup, Bogor, Jawa Barat, Indonesia. Sampel tanah diambil pada Desember 2017, sampel tanah yang digunakan merupakan tanah pada kedalaman (0.0) - (-3.0) meter dibawah lapisan atas tanah aslinya. Tanah yang diambil merupakan benda uji terganggu (disturbed)

\section{Pengujian Awal Sifat Karakteristik Tanah}

Benda uji yang telah tersedia akan dilakukan pengujian awal, tujuan pengujian awal ini agar dapat mengetahui jenis tanah yang telah diambil. Pengujian yang dilakukan berupa:
1. Uji Kadar Air,
2. Uji Gravitasi Spesifik,
3. Uji Batas Konsistensi,
4. Analisa Saringan,
5. Analisa Hidrometer.

Selain pengujian yang dilakukan diatas, akan dilakukan juga pengujian Kompaksi atau Compaction yang bertujuan untuk mendapatkan nilai kadar air optimum. Hal ini dilakukan karena berkaitan dengan proses pembuatan benda uji untuk pengujian CBR yang membutuhkan nilai kadar air optimum.

\section{Pengujian CBR}

Membuat benda uji CBR, tanah yang disiapkan harus lolos saringan no. \#4. Setelah itu sampel dicampur dengan air hingga mencapai kadar air optimum yang didapatkan pada pengujian kompaksi. Selanjutnya dilakukan pemadatan tanah dengan menggunakan modified proctor didalam mold CBR yang sesuai dengan standar ASTM. Proses pembuatan sampel mengacu ke standar ASTM D1883. Setelah proses pemadatan sampel telah selesai, sampel akan diuji menggunakan mesin uji CBR elektrik dengan durasi waktu selama 10 menit. Patokan nilai CBR yang dicapai adalah $2.5 \%, 5.0 \%, 7.5 \%$, dan $10 \%$. Mesin uji CBR yang digunakan pada penelitian ini adalah dengan merek Teclock buatan Jepang dengan kapasitas $6000 \mathrm{lbf}$ atau setara dengan $2721.55 \mathrm{kgf}$. Proses pengujian dilakukan dengan metode trial and error hingga mendapat hasil nilai CBR yang diinginkan.

\section{Pengujian Handheld Vane Shear}

Setelah sampel tanah telah mencapai nilai CBR yang diinginkan, benda uji akan dilakukan pengujian dengan menggunakan Handheld Vane Shear. Pada posisi bagian sampel yang akan diuji, diratakan menggunakan kape agar pada saat Handheld Vane Shear ditekan dapat tegak lurus dan seluruh permukaan vane dapat terpenetrasi secara keseluruhan. Hasil pengujian dapat langsung dibaca pada alat ini, hasil yang dibaca dikalikan dengan koefisien baling-baling yang digunakan. Proses ini dilakukan sebanyak 3 kali pada setiap sisi yang dilakukan pengujian agar didapatkan hasil yang lebih akurat. Pengujian ini dilakukan dengan acuan terhadap standar ASTM D8121. Posisi pengujian secara lebih jelas dapat dilihat pada gambar 2.

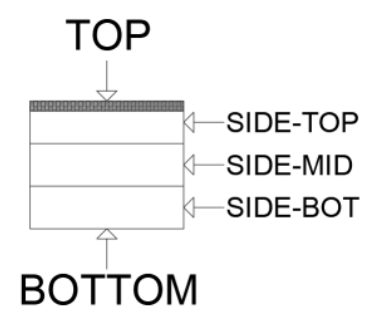

Gambar 2. Posisi-posisi pengujian Handheld Vane Shear

\section{ANALISIS DAN PEMBAHASAN}

Untuk mengetahui jenis tanah yang digunakan, dilakukan pengujian karakteristik tanah seperti gravitasi spesifik, batas konsistensi, grain size analysis, dan pengujian pemadatan standard proctor. Yang hasilnya antara lain:

\section{Hasil Uji Nilai Gravitasi Spesifik}

Dengan nilai Gs yang dapat dilihat pada tabel 2, maka sampel tanah dapat digolongkan sebagai tanah kohesif, sebagai campuran lempung, lanau, pasir, dan lain-lain 
Tabel 2. Hasil Uji nilai Gravitasi Spesifik

\begin{tabular}{cccc}
\hline Keterangan & Sampel 1 & Sampel 2 & Sampel 3 \\
\hline Gs $\left(\mathrm{Tx}=28^{\circ} \mathrm{C}\right)$ & 2.65 & 2.67 & 2.70 \\
\hline Gs $\left(20^{\circ} \mathrm{C}\right)$ & 2.64 & 2.67 & 2.70 \\
\hline Rata-rata Gs & & 2.67 & \\
\hline
\end{tabular}

\section{Hasil Uji Nilai Gravitasi Spesifik}

Hasil yang dapat dilihat berdasarkan hasil yang ditunjukan pada tabel 3 bahwa jenis tanah yang diperoleh dari penelitian yang dilakukan adalah lanau dengan plastisitas tinggi / high plasticity silt $(\mathrm{MH})$.

Tabel 3. Nilai Batas Cair (LL), Batas Plastis (PL), dan Indeks Plastisitas (PI)

\begin{tabular}{cccc}
\hline Keterangan & Sampel 1 & Sampel 2 & Rata-rata \\
\hline Batas Cair (LL)(\%) & 58.96 & 58.47 & 58.71 \\
\hline Batas Plastisitas (PL)(\%) & 30.14 & 33.54 & 31.84 \\
\hline Indeks Plastisitas (PI)(\%) & 28.82 & 24.93 & 26.88
\end{tabular}

\section{Hasil Uji Grain Size}

Tabel 4. Persentase Distribusi Komposisi Butiran Tanah

\begin{tabular}{cccc}
\hline Jenis Tanah & Sampel 1 & Sampel 2 & Rata-rata \\
\hline \% Gravel & 3.42 & 3.04 & 3.23 \\
\hline \% Sand & 5.60 & 7.08 & 6.34 \\
\hline \% Silt & 42.91 & 55.78 & 49.35 \\
\hline \% Clay & 48.07 & 34.10 & 41.09
\end{tabular}

\section{Hasil Uji Pemadatan Standard Proctor}

Dengan pengujian sebanyak 6 kali, nilai kadar air yang diperoleh adalah 26.15\% dan kepadatan kering tanah adalah $15.11 \mathrm{kN} / \mathrm{m}^{3}$.

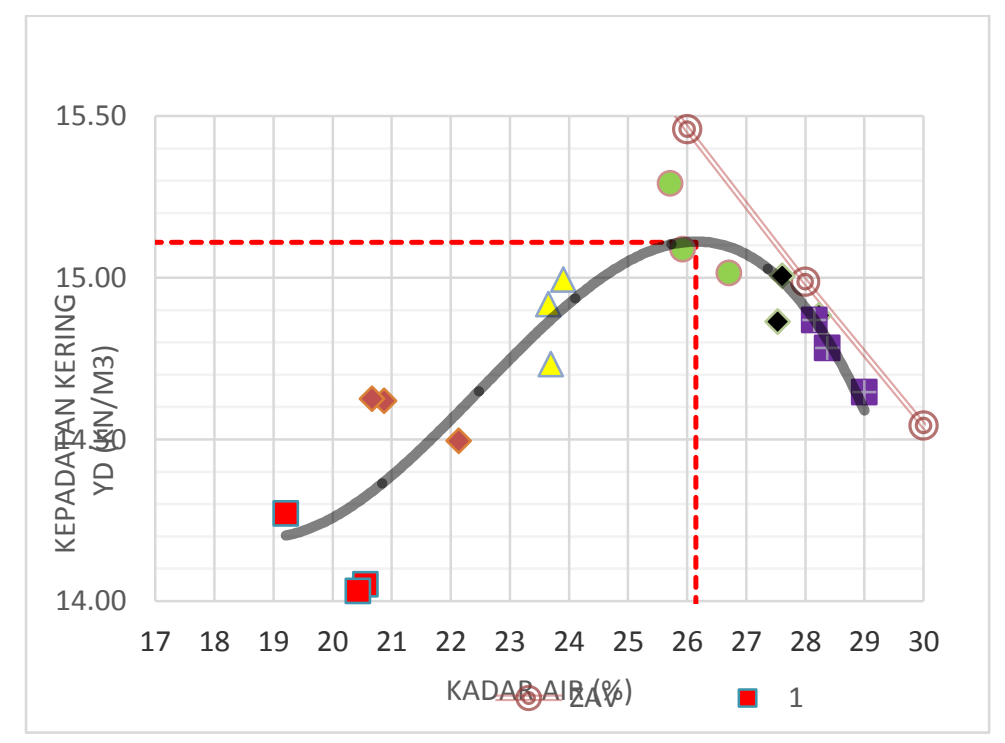

Gambar 3. Kadar Air Optimum dari Uji Pemadatan Standard Proctor 


\section{Hasil Uji California Bearing Ratio (CBR)}

Setelah melakukan beberapa pengujian dan perhitungan uji CBR, data-data yang terkumpul digunakan untuk membuat beberapa benda uji dengan nilai CBR minimum yang diinginkan yaitu 2.5\%, 5.0\%, 7.5\%, dan $10 \%$. Hasil yang didapatkan dapat dilihat pada tabel 5 .

Tabel 5. Hasil Pengujian California Bearing Ratio

\begin{tabular}{cccc}
\hline NILAI CBR (\%) & Jumlah Lapisan & Jumlah Tumbukan & Jumlah Energi $\left(\mathrm{kN} / \mathrm{m}^{3}\right)$ \\
\hline 2.5 & 3.00 & 5.00 & 134 \\
\hline 5.0 & 3.00 & 8.00 & 214 \\
\hline 7.5 & 3.00 & 14.00 & 371 \\
\hline 10 & 3.00 & 48.00 & 1255 \\
\hline
\end{tabular}

\section{Hasil Uji Handheld Vane Shear}

Sesaat setelah pembuatan sampel dengan nilai CBR yang ditentukan selesai, akan dilakukan pengujian kembali dengan menggunakan alat Handheld Vane Shear pada 5 posisi berbeda. Posisi yang dimaksud adalah top, side-top, side-middle, side-bottom, dan bottom. Untuk hasil pengujian dapat dilihat pada tabel 6.

Tabel 6. Hasil Percobaan Handheld Vane Shear

\begin{tabular}{|c|c|c|c|c|c|c|}
\hline \multirow{2}{*}{ NILAI CBR } & \multirow{2}{*}{\multicolumn{2}{|c|}{ POSISI }} & \multicolumn{3}{|c|}{ Angka Bacaan (Su) } & \multirow{2}{*}{$\frac{\mathrm{Su}\left(\mathrm{kg} / \mathrm{cm}^{2}\right)}{\text { Rata-rata }}$} \\
\hline & & & Su1 & $\mathrm{Su} 2$ & $\mathrm{Su} 3$ & \\
\hline \multirow{5}{*}{2.5} & \multicolumn{2}{|r|}{$T O P$} & 5.25 & 6.00 & 6.25 & 5.83 \\
\hline & \multirow{3}{*}{ SIDE } & TOP & 3.00 & 3.50 & 3.00 & 3.17 \\
\hline & & MIDDLE & 3.50 & 3.75 & 3.00 & 3.42 \\
\hline & & ВОTTOM & 3.75 & 3.75 & 3.50 & 3.67 \\
\hline & \multicolumn{2}{|c|}{ BOTTOM } & 6.75 & 6.00 & 6.75 & 6.50 \\
\hline \multirow{5}{*}{5.0} & \multicolumn{2}{|c|}{ TOP } & 7.50 & 7.75 & 7.25 & 7.50 \\
\hline & \multirow{3}{*}{ SIDE } & TOP & 6.00 & 5.75 & 6.00 & 5.92 \\
\hline & & MIDDLE & 6.00 & 6.25 & 6.00 & 6.08 \\
\hline & & ВОTTOM & 6.75 & 6.75 & 7.00 & 6.83 \\
\hline & \multicolumn{2}{|c|}{ ВОTTOM } & 8.25 & 8.50 & 8.50 & 8.42 \\
\hline \multirow{5}{*}{7.5} & \multicolumn{2}{|r|}{ TOP } & 8.50 & 7.50 & 8.75 & 8.25 \\
\hline & \multirow{3}{*}{ SIDE } & TOP & 7.00 & 7.50 & 6.88 & 7.13 \\
\hline & & MIDDLE & 6.25 & 6.25 & 6.50 & 6.33 \\
\hline & & ВОTTOM & 8.88 & 8.75 & 9.00 & 8.88 \\
\hline & \multicolumn{2}{|c|}{ ВОTTOM } & 10.63 & 11.25 & 11.00 & 10.96 \\
\hline \multirow{5}{*}{10} & \multicolumn{2}{|r|}{$T O P$} & 15.00 & 14.50 & 13.75 & 14.42 \\
\hline & \multirow{3}{*}{ SIDE } & $T O P$ & 8.75 & 7.50 & 7.75 & 8.00 \\
\hline & & MIDDLE & 9.75 & 7.25 & 8.50 & 8.50 \\
\hline & & ВOTTOM & 13.25 & 12.25 & 11.25 & 12.25 \\
\hline & \multicolumn{2}{|c|}{ ВOTTOM } & 15.25 & 13.50 & 13.63 & 14.13 \\
\hline
\end{tabular}




\section{Hasil Perhitungan Nilai $K_{0}$}

Berdasarkan perhitungan pada tabel 7 , dapat dilihat bahwa nilai $\mathrm{K}_{0}$ berbanding terbalik dengan nilai uji CBR. Hal ini dikarenakan semakin tinggi nilai uji CBR maka nilai Su juga akan semakin meningkat yang mengakibatkan pada hasil perhitungan menggunakan rumus empiris dimana hasil yang didapatkan yaitu nilai NSpt dan nilai $\varnothing$ mengalami peningkatan juga. Hasil perhitungan dapat dilihat pada tabel 7.

Tabel 7. Hasil Perhitungan Nilai $\mathrm{K}_{0}$

\begin{tabular}{|c|c|c|c|c|c|c|}
\hline \multirow{2}{*}{ NILAI CBR } & \multirow{2}{*}{\multicolumn{2}{|c|}{ POSISI }} & \multirow{2}{*}{$\mathrm{Su}(\mathrm{tsf})$} & $\mathrm{N}(\mathrm{SPT})$ & \multirow{2}{*}{$\varnothing$} & $\mathrm{K}_{0}$ \\
\hline & & & & $\mathrm{Su}=0.179 \mathrm{~N}$ & & $1-\sin \varnothing$ \\
\hline \multirow{5}{*}{2.5} & \multicolumn{2}{|r|}{ TOP } & 6.38 & 35.64 & 41.41 & 0.34 \\
\hline & \multirow{3}{*}{$S I D E$} & $T O P$ & 3.46 & 19.35 & 37.34 & 0.39 \\
\hline & & MIDDLE & 3.74 & 20.88 & 37.72 & 0.39 \\
\hline & & ВОTTOM & 4.01 & 22.40 & 38.10 & 0.38 \\
\hline & \multicolumn{2}{|c|}{ ВОТТОМ } & 7.11 & 39.72 & 42.43 & 0.33 \\
\hline \multirow{5}{*}{5.0} & \multicolumn{2}{|c|}{ TOP } & 8.20 & 45.83 & 43.96 & 0.31 \\
\hline & \multirow{3}{*}{ SIDE } & TOP & 6.47 & 36.15 & 41.54 & 0.34 \\
\hline & & $M I D D L E$ & 6.65 & 37.17 & 41.79 & 0.33 \\
\hline & & BOTTOM & 7.47 & 41.75 & 42.94 & 0.32 \\
\hline & \multicolumn{2}{|c|}{ ВОTTOM } & 9.21 & 51.43 & 45.36 & 0.29 \\
\hline \multirow{5}{*}{7.5} & \multicolumn{2}{|r|}{$T O P$} & 9.02 & 50.41 & 45.10 & 0.29 \\
\hline & \multirow{3}{*}{ SIDE } & $T O P$ & 7.79 & 43.53 & 43.38 & 0.31 \\
\hline & & $M I D D L E$ & 6.93 & 38.70 & 42.17 & 0.33 \\
\hline & & ВОTТОМ & 9.71 & 54.23 & 46.06 & 0.28 \\
\hline & \multicolumn{2}{|c|}{ ВOTTOM } & 11.99 & 66.96 & 49.24 & 0.24 \\
\hline \multirow{5}{*}{10} & \multicolumn{2}{|r|}{ TOP } & 15.77 & 88.09 & 54.52 & 0.19 \\
\hline & \multirow{3}{*}{ SIDE } & $T O P$ & 8.75 & 48.88 & 44.72 & 0.30 \\
\hline & & MIDDLE & 9.30 & 51.94 & 45.48 & 0.29 \\
\hline & & ВОТТОМ & 13.40 & 74.85 & 51.21 & 0.22 \\
\hline & \multicolumn{2}{|c|}{ ВОТТОМ } & 15.45 & 86.30 & 54.08 & 0.19 \\
\hline
\end{tabular}

\section{Perbandingan Persentase Kenaikan Nilai Su terhadap Nilai CBR}

Berdasarkan tabel 8 perbandingan nilai kuat geser $(\mathrm{Su})$ terhadap nilai CBR dapat dilihat bahwa nilai Su pada bagian vertikal mengalami kenaikan yang lebih besar daripada bagian horizontal. Persen kenaikan pada tabel 8 dapat ditampilkan menjadi grafik yang dapat dilihat pada gambar 3 .

Tabel 8. Hasil Perbandingan Nilai Su antara Vertikal dan Horizontal

\begin{tabular}{ccccc}
\hline \multirow{2}{*}{ NILAI CBR $(\%)$} & \multicolumn{2}{c}{$\mathrm{Su}(\mathrm{kg} / \mathrm{cm} 2)$} & \multicolumn{2}{c}{ \% KENAIKAN } \\
\cline { 2 - 5 } & VERTIKAL & HORIZONTAL & VERTIKAL & HORIZONTAL \\
\hline 2.5 & 6.17 & 3.42 & 27.65 & 16.43 \\
\hline 5.0 & 7.96 & 6.28 & 50.16 & 62.01 \\
\hline 7.5 & 9.60 & 7.44 & 67.30 & 77.68 \\
\hline 10 & 14.27 & 9.58 & 100.00 & 100.00 \\
\hline
\end{tabular}




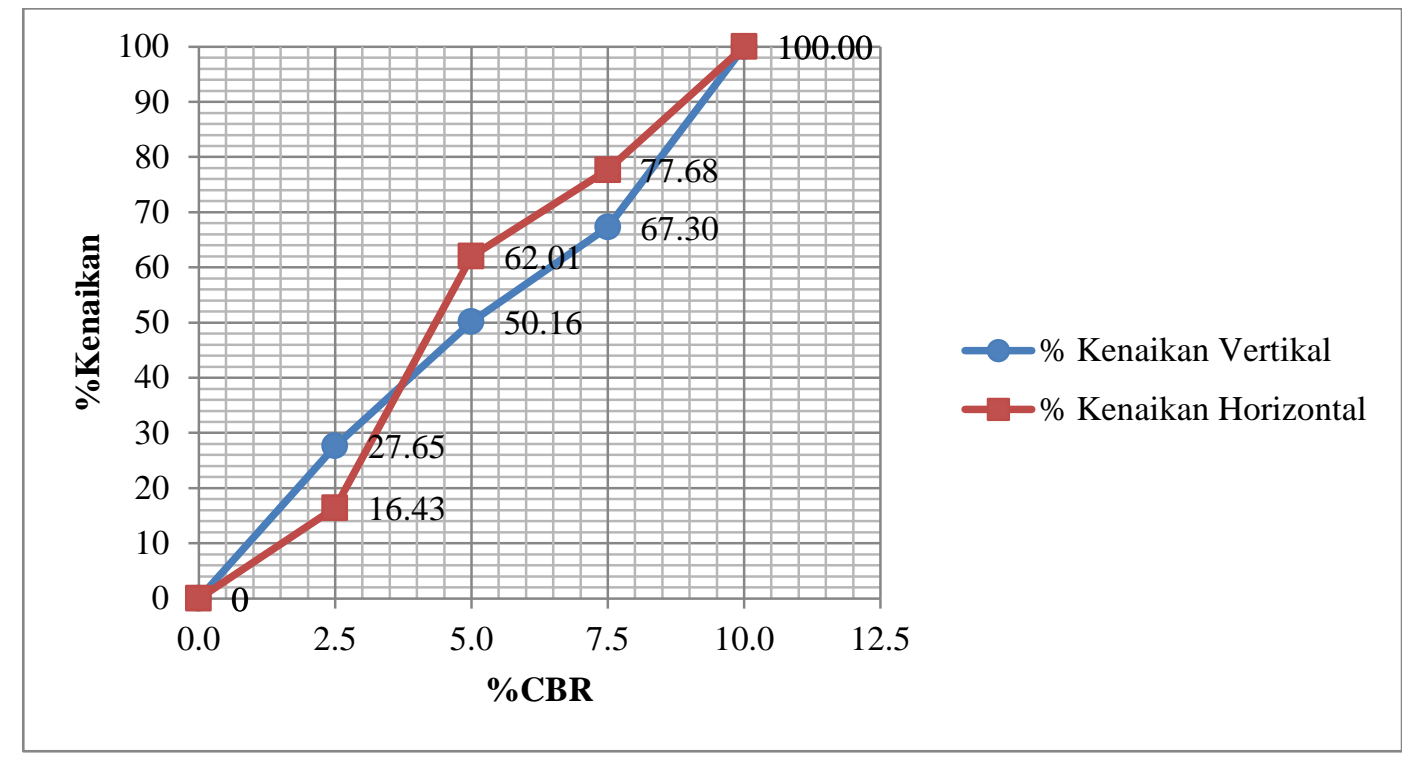

Gambar 4. Persen Kenaikan Nilai Su berdasarkan Nilai CBR

\section{Perbandingan Persentase Penurunan Nilai $K_{0}$ terhadap Nilai CBR}

Berdasarkan nilai koefisien $\mathrm{K}_{0}$ yang didapatkan dari perhitungan, dilakukan rata-rata sesuai dengan posisi dilakukannya proses pengujian dan dihitung persen penurunan antara vertikal dan horizontal. Dimana penurunan lebih besar terjadi pada posisi vertikal dibandingkan dengan penurunan pada posisi horizontal. Untuk lebih detail dapat dilihat pada gambar 4 .

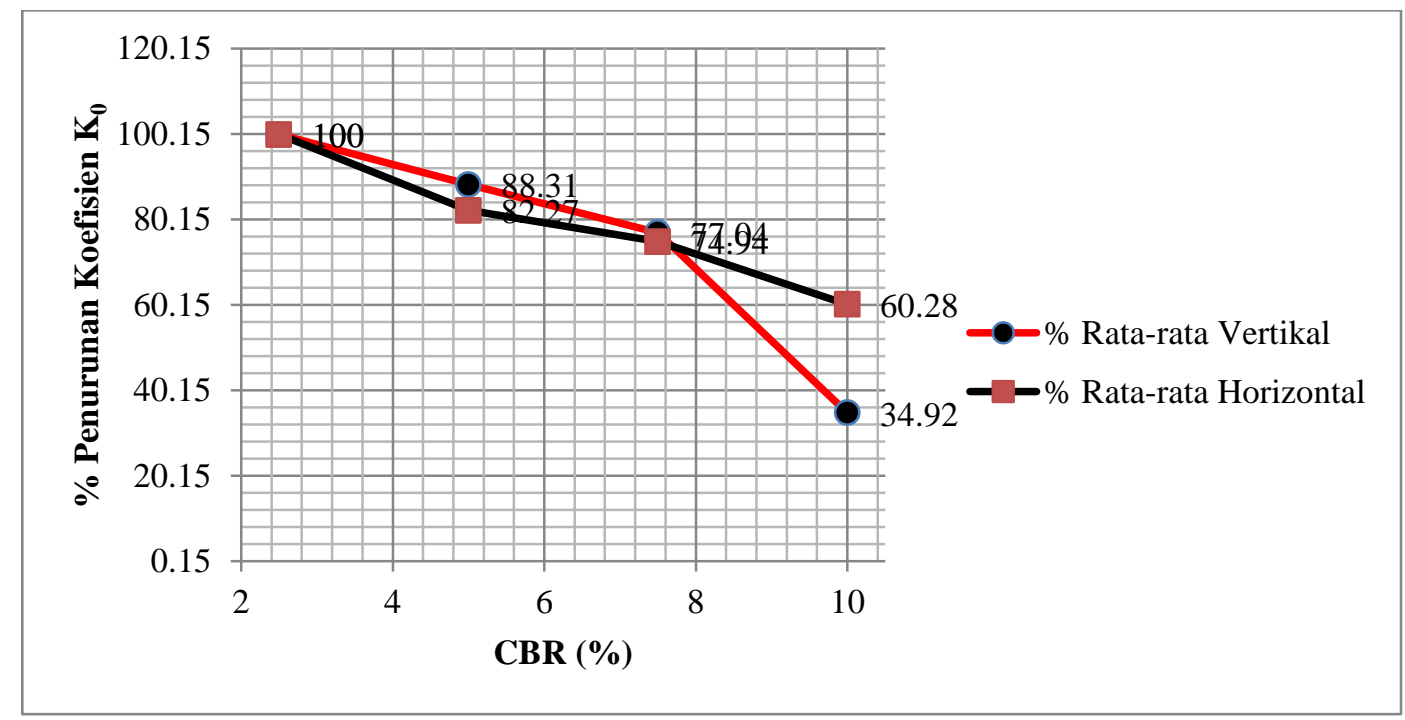

Gambar 5. Persen Penurunan Nilai Koefisien $\mathrm{K}_{0}$ terhadap Nilai CBR

\section{KESIMPULAN}

Berdasarkan pada tabel 6, persentase kenaikan nilai Su pada kepadatan $2.5 \%$ ke $5.0 \%$ adalah sebesar $22.51 \%$ untuk posisi vertikal, dan $45.58 \%$ untuk posisi horizontal. Pada kepadatan $5.0 \%$ ke $7.5 \%$ terjadi peningkatan nilai Su sebesar $17.14 \%$ pada posisi vertikal, dan $15.67 \%$ untuk posisi horizontal. Selanjutnya pada kepadatan $7.5 \%$ ke $10 \%$ terjadi peningkatan nilai Su sebesar $32.70 \%$ pada posisi vertikal dan $22.32 \%$ pada posisi horizontal.

Berdasarkan tabel 7, persentase nilai $\mathrm{K}_{0}$ pada kepadatan $2.5 \%$ hingga $5 \%$ mengalami penurunan sebesar $11.69 \%$ untuk posisi vertikal dan $17.73 \%$ untuk posisi horizontal. Pada kepadatan $5.0 \%$ hingga $7.5 \%$, persentase nilai $\mathrm{K}_{0}$ mengalami penurunan sebesar $11.27 \%$ pada posisi vertikal dan $7.33 \%$ pada posisi horizontal. Selanjutnya pada kepadatan $7.5 \%$ hingga $10 \%$, persentase nilai $\mathrm{K}_{0}$ mengalami penurunan sebesar $42.12 \%$ pada posisi vertikal dan $14.66 \%$ pada posisi horizontal. 
Dengan hasil pengujian korelasi nilai CBR terhadap nilai tegangan tanah ini dapat menjadikan masukan pada saat mendesain suatu konstruksi bangunan misalnya tegangan horizontal tanah terhadap dinding penahan tanah yang meningkat jika tanah sekitarnya dilakukan pemadatan.

\section{DAFTAR PUSTAKA}

Anggour, S. M. 2002. Updating Bearing Capacity - SPT Graphs. Maryland: Civil and Environmental Engineering Department. University of Maryland

Bowles, J. E. 1979. Physical and Geotechnical Properties of Soils. New York: McGraw-Hill.

Budi, G. S. 2011. Pengujian Tanah di Laboratorium. Yogyakarta: Graha Ilmu.

Das, Braja M. 1995. Mekanika Tanah (Prinsip-prinsip Rekayasa Geoteknis). Trans. Noor Endah Mochtar dan Indrasurya B. Mochtar. Jilid 1. Jakarta: Erlangga.

Hardiyatmo, H. C. 2002. Mekanika Tanah 1 \& Mekanika Tanah II. Jilid 1. Edisi 3. Jakarta: PT Gramedia Pustaka Umum.

Sowers, G. F. 1979. Introductory Soil Mechanics and Foundations: Geotechnical Engineering. Edisi 4. New York: MacMillan. 
